\title{
Hyflex CM and EDM files: revolutionizing the art and science of endodontics
}

\begin{abstract}
Success in endodontic therapy relies on thorough cleaning and shaping of root canal system followed by its complete obturation. With increase in number of cases reporting for endodontic therapy, dental professionals have to deal with more complicated cases such as those with very fine and curved canals. Standard Nickel Titanium rotary endodontic files, because of their shape memory property and larger tapers can often not serve well for such difficult cases. The introduction of controlled memory files (Hyflex, Coltene) and the new generation Electrical discharge machine files (EDM, Coltene) have revolutionized Endodontics by their extraordinary properties which have begun a new era in Dentistry.
\end{abstract}

Keywords: controlled memory, electric discharge machining, endodontic treatment, hyflex
Volume 5 Issue 7 - 2016

\author{
Harpreet Singh,' Pooja Kapoor ${ }^{2}$ \\ 'Department of Conservative Dentistry and Endodontics, Gian \\ Sagar Dental College and Hospital, India \\ 2Department of Orthodontics and Dentofacial Orthopaedics, \\ Gian Sagar Dental College and Hospital, India
}

Correspondence: Harpreet Singh, Department of Conservative Dentistry and Endodontics, Gian Sagar Dental College and Hospital, India, Email hsgentledental@gmail.com

Received: October 29, 2016 | Published: December 29, 2016

\section{Introduction}

Successful Endodontic therapy is based on cumulative results of complete debridement and disinfection of root canal system, followed by a three dimensional obturation. ${ }^{1}$ However, certain anatomic complexities such as very fine canals such as those commonly encountered in geriatric cases and extremely curved canals can pose a real challenge to the treating dentist. ${ }^{2}$ Inability to completely negotiate the entire root canal up to its physiologic terminus, often results in endodontic failure. ${ }^{3}$ Rotary Endodontic Instruments brought a paradigm shift in the field of Endodontics. ${ }^{4,5}$ However, as the use of these fast cutting Ni Ti Files progressed across the globe, the advantages were paralleled by the limitations and drawbacks. ${ }^{6}$ The instrument related procedural errors such as ledge formation, transportation, perforations etc. became increasingly common, leading to major concerns over the use of aggressive rotary endodontic files. This led to the researchers' world over to rationalize the possible cause of such mishaps. Eventually a concept emerged which revolutionized the technology of rotary endodontic files, which was based on 'Controlled memory' in contrast to the classical 'Shape memory' one. A new Nitinol rotary instrument files with controlled memory (Hyflex ${ }^{\circledR}$ CM, Coltene) was introduced which was machined from a wire (termed CM-wire) previously subjected to a proprietary, novel, thermomechanical processing procedure. Clinical and experimental studies have indicated that these new Hyflex ${ }^{\circledR} \mathrm{CM}$ rotary instruments have outstanding clinical fatigue resistance. ${ }^{7}$ The Controlled memory effect helps the file to retain the shape of the canal even when it is out of the canal (Figure 1). This property is responsible for avoiding procedural errors such as ledge formation, transportation, perforations etc. the extreme flexibility and lesser taper of these files make them very advantageous in curved canal cases. Of late, another major transformation has happened in file technology which has taken the endodontics to a next level. This has been introduction of EDM files (Figure 2). EDM stands for Electrical Discharge Machining. This is a unique process of making the files process using electric discharge machining. Work pieces are machined in the EDM manufacturing process by generating a potential between the work piece and the tool. The sparks generated in this process cause the surface of the material to melt and evaporate. This creates the unique surface of the new Niti files and makes the Hyflex EDM files stronger and more fracture resistant. ${ }^{8}$ This entirely unique combination of flexibility and fracture resistance makes it possible to reduce the number of files required for cleaning and shaping during root canal treatment without having to compromise preservation of the root canal anatomy.

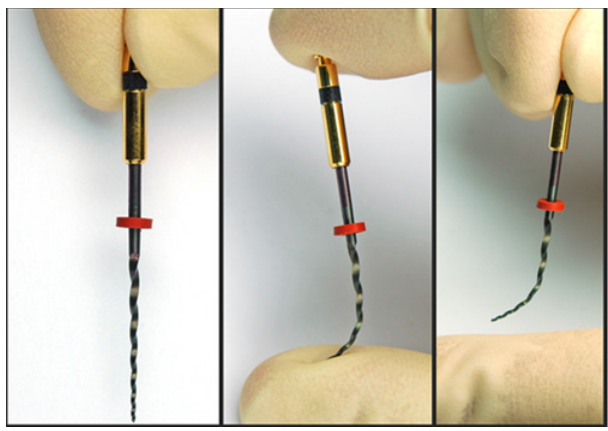

Figure I Controlled Memory effect of Hyflex files.



Figure 2 EDM 'One file’. 


\section{Case reports}

A 25 years old male came with the complaint of pain and sensitivity in mandibular right first molar. After clinical and radiographic examination and endodontic therapy was advised. After anaesthetizing the tooth, access preparation was done and canal orifices were located with DG 16 endodontic explorer. Initial negotiation of the root canals was confirmed with K-file 10. Thereafter Hyflex files were used in a sequential order as per the manufacturer's instructions in the mesial canals as these were fine and curvy. A 0.08 taper (25 No, 19mm length) file was first used to perform the coronal flare. Thereafter, 0.04 taper file (15 No.) was used up to the working length, this was followed by the use of next size 0.04 taper files in sequence $(20$ No. and 25 No.). The distal canals were prepared using Hyflex EDM files, which is a set of 3 files. The Orifice shaper, the Glide path file and the One file. Warm 5\% sodium hypochlorite (warmed using Syringe warmer, Coltene) was used throughout the procedure as the irrigant. Calcium hydroxide was given as intracanal medicament. At next appointment patient was asymptomatic. Master cone radiograph revealed proper fitting of respective GP cones. Canals were dried with paper point and obturation done by using single cones of corresponding taper and size as MAF, using Gutta Flow 2 sealer (Coltene) (Figure 3) a similar case of mandibular first molar of a 32 year old male was completed using Hyflex CM and EDM files (Figure 4). Canals which are wide and relatively straight can be treated using EDM files alone as shown step-wise in Figure 5, a case of Maxillary first premolar of an 18 year old patient.

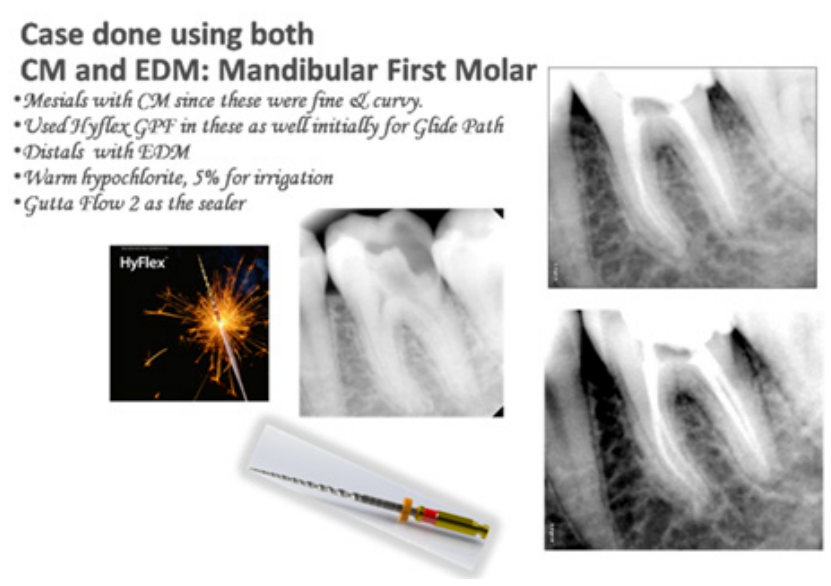

Figure 3 Endodontic management of Mandibular first molar.

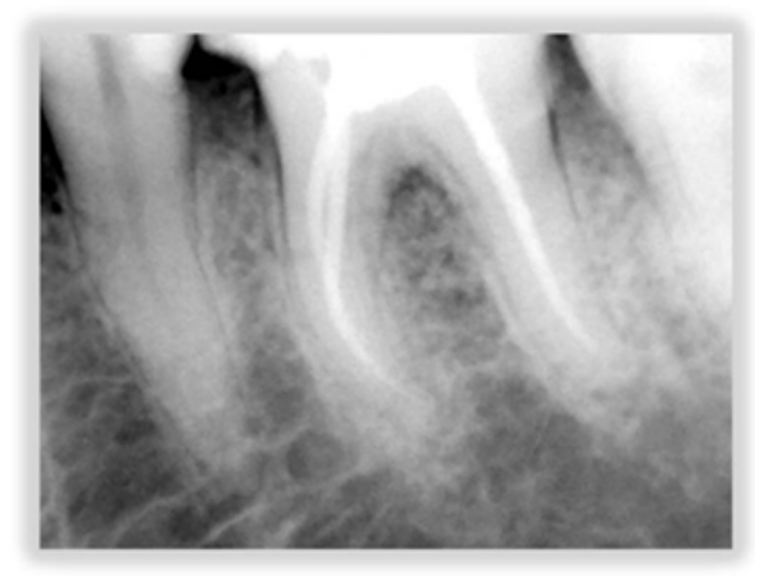

Figure 4 Endodontic treatment completed of mandibular first molar.

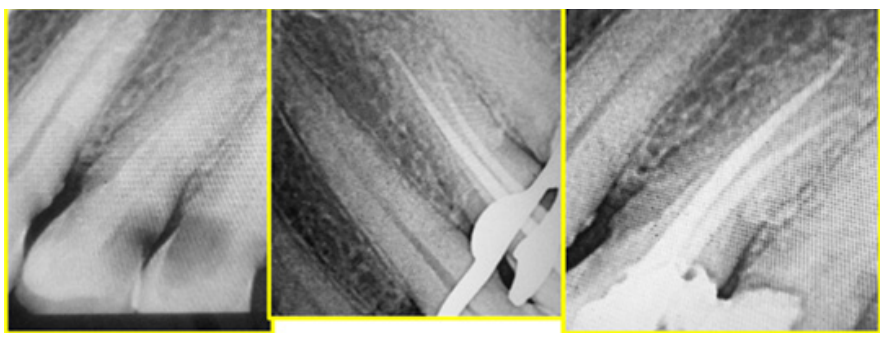

Figure 5 Endodontic management of Maxillary first Premolar.

\section{Discussion}

Root canal treatment should result in the thorough mechanical and chemical debridement of the entire pulp cavity, followed by a three dimensional obturation. Larger NiTi instruments may transport the canal space, causing strip perforations because of their rigidity. This issue has been easily resolved by the introduction of Controlled Memory files (Hyflex CM, Coltene), which retain their shape in curved canals and do not possess the 'Spring back action', thereby avoiding any perforation. The conventional NiTi files have another drawback of not giving a 'warning sign' before breakage (unlike stainless steel files, which show such signs in the form of unwinding of flutes, or presence of a shiny spot on the file, indicating that the file should be discarded). Hyflex files have overcome this problem with the unique characteristic of rewinding of the file (Figure 6) after autoclaving. ${ }^{9}$ If the file does not rewind, it indicates that it needs to be discarded. This is a very useful criteria for the clinician to decide when to discard the file. A unique combination of 3 and 4 fluted file designs has been incorporated in these files to provide optimum performance and strength. Also, these files can be prebent similar to stainless steel files before introduction in the curved canals. In general, there are a few technical considerations to be kept into account while using Hyflex files. The number of times the instruments can be re-used depends on the treatment and procedure. Instruments must be inspected before and after use. Hyflex ${ }^{\circledR} \mathrm{CM}$ files may respond to pressure, torque, and resistance with a lengthening/ opening up of the spirals. During autoclaving, the instruments can regain their shape, if it doesn't, the file should be discarded (Figure 6). Electrical discharge machining (EDM), sometimes also known as spark machining, spark eroding, burning, die sinking, wire burning or wire erosion, is a manufacturing process whereby a desired shape is obtained using electrical discharges (sparks). Principle of Electrical Discharge Machining (EDM) technique is a controlled metal-removal process that is used to remove metal by means of electric spark erosion. In this process an electric spark is used as the cutting tool to erode the work piece to produce the finished part to the desired shape. The metal-removal process is performed by applying a pulsating $(\mathrm{On} /$ Off) electrical charge of high-frequency current through the electrode to the work piece. This erodes very tiny pieces of metal from the work piece at a controlled rate. The repeated bombarding of the alloy with sparks melts the material or even leads to evaporation in some places. The result is a file with a distinctly textured surface where heat creates a new surface hardness. Spark erosion generates a unique, hardened surface, which improves cutting performance even further. ${ }^{10}$ Hyflex EDM files are one of the first endodontic instruments manufactured with EDM technology. There are three different cross section designs in single file. The rectangular cross section at the tip provides more 'core material', which results in high resistance to breakage of these files. Then the cross section becomes trapezoidal in the middle of the 
file and finally near the handle, the cross section changes to triangle which keeps the file more flexible there. It can be labeled as a unique combination of flexibility and strength.

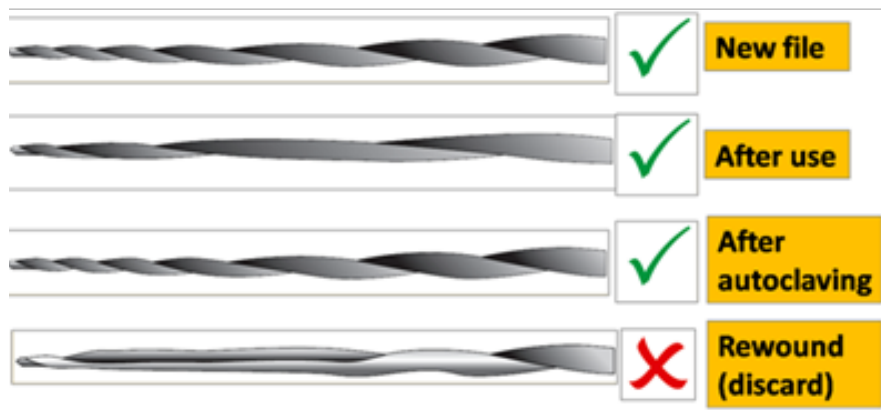

Figure 6 Winding and unwinding of Hyflex CM files.

\section{Conclusion}

Endodontics has seen big changes in terms of both technology and technique. The use of new generation instruments such as Controlled Memory files and EDM file can definitely be an asset to the practicing dental professionals in managing difficult cases with much ease and lesser mishaps.

\section{Acknowledgments}

None.

\section{Funding}

None.

\section{Conflicts of interest}

The authors declare there is no conflict of interests.

\section{References}

1. Nguyen TN. Obturation of the root canal system. In: Cohen S, Burns RC, editors. Pathways of the Pulp. 4th ed. USA: Mosby; 1987. pp. 183-194.

2. Schafer E, Diez C, Hoppe W, et al. Roentgenographic investigation of frequency and degree of canal curvatures in human teeth. $J$ Endod. 2002;28(3):211-216.

3. Frank J, Vertucci. Root canal morphology and its relationship to endodontic procedures. Endodontic Topics. 2005;10(1):3-29.

4. Gambarini G. Rationale for the use of low torque endodontic motors in root canal instrumentation. Endod Dent Traumatol. 2000;16(3):95-100.

5. Markus Haapasalo, Ya Shen. Evolution of nickel-titanium instruments: from past to future. Endodontic topics. 2013;29(1):3-17.

6. Gambarini G. Advantages and disadvantages of new torque-controlled endodontic motors and low-torque NiTi rotary instrumentation. Aust Endod J. 2001;27(3):99-104.

7. Ninan E, Berzins DW. Torsion and bending properties of shape memory and superelastic nickel-titanium rotary instruments. $J$ Endod. 2013;39(1):101-104.

8. Pedulla, Lo Savio, Boninelli, et al. Torsional and cyclic fatigue resistance of a new nickel-titanium instrument manufactured by electrical discharge machining. J Endod. 2015;42(1):156-159.

9. Dina Al Sudani. Topographic analysis of HyFlex® Controlled memory nickel-titanium files. J Int Oral Health. 2014;6(6):1-4.

10. Pirani, Generali, Sassatelli, et al. Wear analysis and cyclic fatigue resistance of electro discharge machined NiTi rotary instruments. Giornale Italiano di Endodonzia. 2016;30(1):64-68. 